\title{
AdventureSECO: Jogo Educacional para o Ensino de Conceitos sobre Ecossistemas de Software
}

\author{
Thaís Ferreira $^{1}$, Juliana Fernandes ${ }^{2,3}$, Davi Viana ${ }^{4}$, Luis Rivero ${ }^{4}$, Rodrigo Santos ${ }^{2}$ \\ ${ }^{1}$ Escola de Informática Aplicada - UNIRIO - Rio de Janeiro - Brasil \\ ${ }^{2}$ Programa de Pós-Graduação em Informática - UNIRIO - Rio de Janeiro - Brasil \\ ${ }^{3}$ Instituto Federal do Piauí - IFPI - Teresina- Brasil \\ ${ }^{4}$ Programa de Pós-Graduação em Ciência da Computação - UFMA - São Luís - Brasil \\ \{thais.ferreira,juliana.costa,rps\} euniriotec.br, \\ davi.viana@lsdi.ufma.br, luisrivero@nca.ufma.br
}

\begin{abstract}
This work presents an educational game for exploring concepts about software ecosystems. The goal is to leverage students' interest, keeping them motivated and immersed in the learning activity. The game was developed following the ENgAGED (EducatioNAl GamEs Development) process and based on Construct 2 tool.
\end{abstract}

Resumo. Este trabalho apresenta um jogo educacional com o intuito de apresentar conceitos de ecossistemas de software e despertar o interesse dos alunos, mantendo-os motivados e imersos na atividade de aprendizagem. $O$ jogo foi desenvolvido seguindo o processo ENgAGED (EducatioNAl GamEs Development) e baseado na ferramenta Construct 2.

\section{Introdução}

A evolução tecnológica tem alterado a forma como software é desenvolvido [Meireles e Bonifácio 2015]. Nesse sentido, a Engenharia de Software (ES) tem progredido em pesquisa teórica e aplicada, apresentando uma gama de novos conhecimentos do mercado atual e.g., Ecossistemas de Software (ECOS) e Sistema de Sistemas (SoS) [Santos et al. 2013]. Essa evolução também trouxe mudanças em como usuários finais e desenvolvedores interagem e aprendem sobre seus processos [Yamaguti et al. 2017]. Nesse contexto, aulas puramente expositivas não são capazes de transferir os conhecimentos acerca de ES de forma satisfatória, pois o conteúdo é extenso e de difícil abstração, o que acaba tornando a aula monótona e pouco produtiva. Além disso, a ES é uma disciplina de caráter prático.

Nesse sentido, os jogos educacionais são vistos como estratégia inovadora para o ensino de Computação [Backlund e Hendrix 2013]. O design de jogos traz princípios e elementos que podem ser incorporados ao processo de ensino-aprendizagem, tais como: diversão combinada com dificuldade; controle do processo de aprendizagem por parte do aluno; gameplay para manter o aluno constantemente desafiado e motivado; e mecânicas assimétricas para diversificar a experiência de aprender [Mattar e Nesteriuk 2016]. O objetivo deste artigo é apresentar um jogo digital do gênero plataforma para auxiliar o processo de ensino-aprendizagem de ECOS. O jogo permite que o estudante possa perceber conceitos que não são bem assimilados por meio de aulas expositivas [Yamaguti et al. 2017]. Neste contexto, um ECOS consiste em um conjunto de atores e 
VII Congresso Brasileiro de Informática na Educação (CBIE 2018)

Anais do XXIX Simpósio Brasileiro de Informática na Educação (SBIE 2018)

artefatos que interage sobre uma plataforma tecnológica comum, desenvolvendo extensões, e.g., ecossistemas iOS, Android, Microsoft, Eclipse e SAP.

\section{Metodologia}

Para a concepção do jogo, foram realizadas as seguintes etapas: (i) levantamento bibliográfico dos temas "engenharia de software", "jogos para o ensino de engenharia de software" e "ecossistemas de software"; (ii) estudo sobre o ensino de ES com jogos; (iii) identificação de dificuldades no ensino de temas modernos em ES por meio de um survey com professores da área no Brasil; e (iv) desenvolvimento do jogo baseado no processo ENgAGED. ENgAGED é um processo iterativo de desenvolvimento de jogos para ensino de computação, que envolve as etapas de análise, projeto, desenvolvimento, execução e avaliação [Battistella e Wangenheim 2015].

$\mathrm{Na}$ análise, foi realizada a caracterização dos aprendizes; a identificação do curso e disciplina nos quais o jogo será aplicado; e os objetivos da aprendizagem, ou seja, o que se espera que o aluno saiba após a experiência com o jogo. No projeto, foi definido como o aluno irá aprender com o jogo (quais regras e feedbacks). No desenvolvimento, foram definidos o gênero do jogo (platformer), objetivo, plataforma de distribuição (desktop/browser), game engine (Construct 2), a narrativa, os elementos do jogo e o seu funcionamento. As etapas de execução e avaliação estão em andamento.

\section{O Jogo AdventureSECO}

No AdventureSECO, o jogador deve "viver" o sonho de um menino que deveria ter estudado para a prova de ECOS, mas não o fez. O sonho é uma mistura de conceitos sobre ECOS que foram lidos rapidamente pelo garoto, com o jogo de invasão alienígena que ele estava jogando ao invés de estudar. $\mathrm{O}$ objetivo do jogador é passar pelas quatro fases do sonho (representando fases do ciclo de vida de ECOS: nascimento, expansão, liderança e autorrenovação) e tentar aprender o máximo possível para que esse aprendizado fique salvo no subconsciente do menino e ele possa "ir bem" na prova.

Cada fase apresenta missões e quebra-cabeças sobre as características das fases do ciclo de vida do ECOS. A fase de nascimento, por exemplo, é caracterizada pela identificação das necessidades do cliente, definição dos produtos ou serviços, atração de potenciais participantes por meio de capital, potencial de lucro e infraestrutura tecnológica. Sendo assim, o jogador enfrentará desafios/obstáculos para coletar os itens que representam esses elementos, tanto para passar de fase como para angariar pontos. Os pontos de ECOS são usados para calcular a posição do jogador na classificação geral. Quanto maior a pontuação, melhor será a classificação. Ao final de cada fase, o jogador terá um mini quiz com o intuito de reforçar o que o aluno absorveu ao passar pela fase. Para cada resposta correta, o jogador ganhará pontos de ECOS.

No decorrer do sonho, o jogador fará o papel de Keystone, i.e., o principal interessado no sucesso do ECOS (e.g., papel da Google no ECOS Android). O jogador deverá tomar cuidado com os empecilhos que encontrará em seu caminho, como o Dominator (ator que extrai valor, afetando sua saúde e sustentabilidade, e.g. o papel da Microsoft no ECOS BrOffice), representado por inimigos que, ao encostarem e/ou atacarem o jogador, causam dano ao mesmo. Para que o jogador recupere sua vida, ou seja, a saúde do seu ECOS, ele poderá coletar três itens com a mesma cor da barra de vida. Esses itens representam os indicadores de saúde de um ECOS, que são: (i) 
VII Congresso Brasileiro de Informática na Educação (CBIE 2018)

Anais do XXIX Simpósio Brasileiro de Informática na Educação (SBIE 2018)

robustez, mede o nível de recuperação de perturbações na sua estrutura; (ii) produtividade, mede o nível de atividade; e (iii) criação de nicho, mede a criação de oportunidades. O jogador deve estar atento à saúde do ECOS pois, se a vida for zerada, o ECOS morre. A Figura 1 ilustra a primeira fase com alguns elementos.

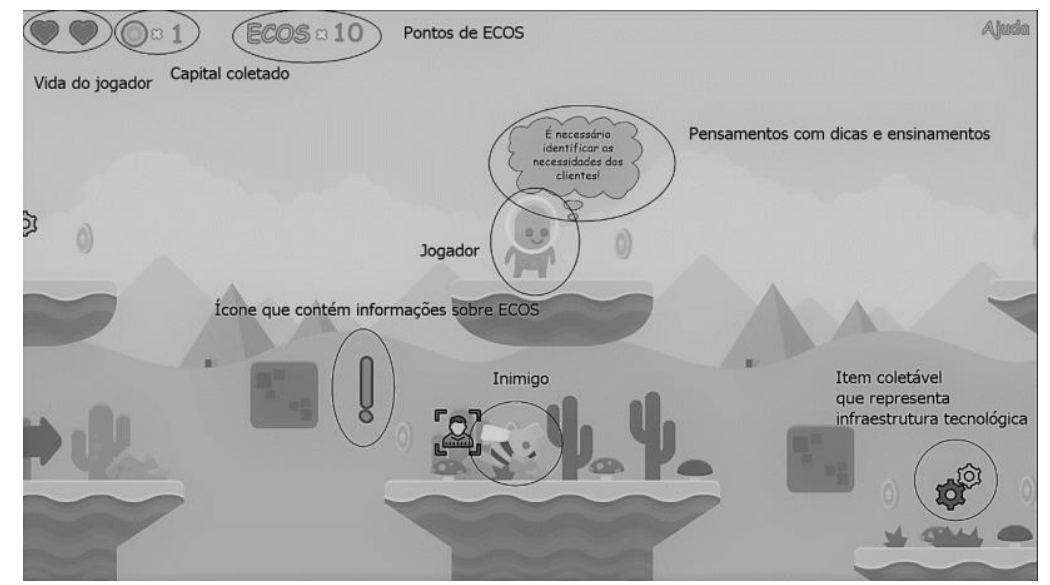

Figura 1. Imagem da primeira fase do jogo.

\section{Conclusão}

Este trabalho auxilia o processo de ensino-aprendizagem de ES ao propor uma ferramenta lúdica para o ensino e revisão de conceitos de ECOS na disciplina de ES em cursos superiores da área de Computação. A ferramenta consiste em um jogo de plataforma educacional digital. Como trabalhos futuros, as etapas execução e avaliação do processo ENgAGED estão sendo realizadas em turmas de Sistemas de Informação e um experimento será realizado para atestar os benefícios no processo de aprendizagem.

Agradecimentos. A primeira autora agradece ao apoio da UNIRIO.

\section{Referências}

Backlund, P. e Hendrix, M. (2013) "Educational games - Are they worth the effort? A literature survey of the effectiveness of serious games", In: Proc. of the 5th Int. Conf. on Games and Virtual Worlds for Serious Applications, Bournemouth, UK.

Battistella, P. e Wangenheim, C. (2015) "ENgAGED: Processo de Desenvolvimento de Jogos para Ensino em Computação". Relatório Técnico INCoD/GQS.01.2015.P, Instituto Nacional de Convergência Digital, UFSC, Florianópolis, Brasil.

Mattar, J. e Nesteriuk, S. (2016) "Estratégias do Design de Games que podem ser incorporadas à Educação a Distância". RIED, v. 19, n. 2, pp. 91-106.

Meireles, M. e Bonifácio, B. (2015) "Uso de Métodos Ágeis e Aprendizagem Baseada em Problema no Ensino de Engenharia de Software: Um Relato de Experiência", In: Anais do XXVI Simpósio Brasileiro de Informática na Educação, Maceió, 180-189.

Santos, R. et al. (2013) "Ecossistemas de Software: Um Novo Espaço para a Construção de Redes e Territórios envolvendo Governo, Sociedade e a Web", In: C. Werner et al. (Org.), Políticas Públicas: Interações e Urbanidades, Letra Capital, 337-366.

Yamaguti, M. H. et al. (2017) "AGES: An Interdisciplinary Space Based on Projects for Software Engineering Learning”, In: 31st SBES, Fortaleza, Brazil, 368-373. 